\title{
Análise da disposição de efluentes na área das dunas de Alagamar (Parnami- rim-Natal/RN): integração de dados geofísicos e hidrogeológicos
}

\author{
Leandson Roberto Fernandes de Lucena ${ }^{1}$, Josibel Gomes de Oliveira Jr ${ }^{2}$ \\ \& José Braz, Diniz, Filho
}

\begin{abstract}
Resumo O presente artigo representa uma síntese de estudos desenvolvidos com o objetivo de avaliar a área denominada de Dunas de Alagamar (faixa costeira entre Parnamirim e Natal-RN) como destino de efluentes tratados. A metodologia geral adotada é fundamentada no emprego de técnicas investigativas multidisciplinares, particularmente de hidrogeologia e geofísica (GPR). Em termos de resultados, o levantamento geofísico com GPR evidenciou uma espessura da porção insaturada, sobretudo da Unidade Dunas Móveis já nas proximidades da linha de costa, bastante reduzida. Tais valores variaram de 3 a 12 metros, sendo a espessura de 7 metros representando uma média local desse parâmetro. As condições hidráulicas deste meio insaturado na área em estudo mostraram-se com dois comportamentos distintos. As areias inconsolidadas aflorantes que compõem as dunas apresentam permeabilidade da ordem de $10^{-2} \mathrm{~cm} / \mathrm{s}$, ao passo que os sedimentos da porção superior da Formação Barreiras, sotopostos às dunas, exibem permeabilidade da ordem de $10^{-4} \mathrm{~cm} / \mathrm{s}$. Esses valores sugerem um cenário de elevadas velocidades de infiltração de líquidos (água ou efluentes tratados) nos sedimentos dunares até alcançar o topo da Formação Barreiras, quando a intensidade da infiltração é diminuída substancialmente. Considerando-se as características hidráulicas prevalecentes, somado com a geometria do meio insaturado ora caracterizado, avalia-se como improvável a efetiva destinação final de efluentes tratados através da infiltração direta no solo/subsolo da área, sobretudo com descargas da ordem de $5.000 \mathrm{~m}^{3} / \mathrm{h}$.
\end{abstract}

Palavras-chave: Dunas de Alagamar-RN, infiltração de efluentes, GPR.

\begin{abstract}
Analysis of the disposition of effluents in the area of the Alagamar dunes (ParnamirimNatal/RN state): integration of geophysical and hydrogeological data. The present paper represents a synthesis of studies that were developed with the goal of evaluating the area of Alagamar Dunes (coastal strip among Parnamirim and Natal in Rio Grande do Norte State, Brazil) as destiny of treated effluents. The adopted general methodology is based in the employment of multidisciplinary techniques, particularly of hydrogeology and geophysics (GPR). Results from GPR revealed a quite reduced unsaturated layer portion, which lies on the top of all of the Dunes Unit (Movable) close to the coast line. Thickness values of this unsaturated layer varied from 3 to 12 meters and had an average value of 7 meters. The hydraulic conditions of this unsaturated zone in the area exhibited two different behaviors. The supperficial unconsolidated sand which composes the dunes presented (average) permeability of the $10^{-2} \mathrm{~cm} / \mathrm{s}$, whilst sediments of the upper portion of the Barreiras Formation which lies under the dunes, exhibit permeability of the order of $10^{-4} \mathrm{~cm} / \mathrm{s}$. Those values suggest a scenery of high liquid infiltration velocity (fresh water or treated effluents) in the sediments of the dunes until the fluid reaches the Barreiras Formation top when the intensity of the infiltration decreases substantially because of the decreasing permeability in this formation. Considering the prevalent hydraulic characteristics and the geometry of the unsaturated zone, it is concluded as unlikely the effective final destination of treated effluents through the direct infiltration in the surface/subsurface of the area, specially if we consider discharges of the order of $5.000 \mathrm{~m}^{3} / \mathrm{h}$.
\end{abstract}

Keywords: Alagamar sand dunes-RN State, infiltration of effluents, GPR.

INTRODUÇÃO A Companhia de Águas e Esgotos do Rio Grande do Norte-CAERN vem desenvolvendo ultimamente pesquisas voltadas para o incremento do sistema de tratamento e destinação final de efluentes, particularmente aqueles provenientes da zona sul de Natal e adjacências.
Nesse contexto, a área pertencente ao Ministério da Defesa e onde se situa o Centro de Lançamento da Barreira do Inferno-CLBI (faixa costeira entre Parnamirim e Natal), apresenta-se ainda como uma região protegida, tanto em termos geoambientais dos campos dunares, como também do manancial hídrico subterrâ-

1 - UFRN, Departamento de Geofísica, Natal (RN), Brasil. E-mail: leandson@geofisica.ufrn.br

2 - UFRN, Departamento de Geofísica, Natal (RN), Brasil. E-mail: josibel@geofisica.ufrn.br

3 - UFRN, Departamento de Geologia, Natal (RN), Brasil. E-mail: brazdf@geologia.ufrn.br 
neo. A sua importância sob o ponto de vista desta potencialidade hídrica é bastante significativa, sobretudo por resultados parciais obtidos pela CAERN que apontam para a locação de uma bateria de poços estratégica ao longo da "Rota do Sol" (RN-063) que poderia ser executada com o objetivo de reforçar o abastecimento de toda a zona sul. Por outro lado, uma subárea do CLBI conhecida como Dunas de Alagamar (Fig. 1), representada por uma faixa paralela a praia e com cerca de $2,5 \mathrm{~km}$, vem sendo cogitada para receber, em valas, águas residuais tratadas oriundas da mesma zona sul, sob a justificativa de representar uma recarga artificial local e constituir-se num reforço hidráulico preventivo contra a cunha salina.

Dessa forma, a pesquisa em questão, coordenada pela Fundação Norte-Rio-Grandense de Pesquisa e Cultura-FUNPEC e desenvolvida em conjunto com a Universidade Federal do Rio Grande do Norte-UFRN, objetivou avaliar a viabilidade da área denominada " $\mathrm{Du}$ nas de Alagamar" como receptora de efluentes tratados. A metodologia geral foi fundamentada no emprego de técnicas geofísicas (GPR) e hidrogeológicas na caracterização do meio físico dos pacotes de dunas e porção superior da Formação Barreiras sotoposta (espessuras, parâmetros hidráulicos e balanço hídrico local).

O CONTEXTO GEOLÓGICO E HIDROGEOLÓGICO REGIONAIS A Geologia regional é constituída estratigraficamente por duas seqüências básicas: uma não aflorante, envolvendo o embasamento cristalino PréCambriano e sedimentos da bacia sedimentar mesozóica, ambos detectadas em perfis de poços da região, e outra aflorante, representada por sedimentos cenozóicos. Estes últimos compreendem sedimentos argilo-arenosos a conglomeráticos da Formação Barreiras e arenosos da Formação Potengi, sotopostos aos sedimentos quaterná- rios, onde se incluem os beachrocks, arenitos praiais e as diversas gerações de dunas móveis e fixas.

A caracterização estrutural regional, abordada em trabalhos prévios tais como Bezerra et al. (1993), Lucena \& Queiroz (1996), Coriolano et al. (1998), dentre outros, evidenciaram uma complexa estruturação na área, caracterizada nas direções gerais NW-SE, NE-SW e E-W.

O contexto hidrogeológico é constituído por uma zona não saturada e outra saturada em água normalmente de excelente qualidade físico-química e bacteriológica. A zona não saturada é predominantemente representada por sedimentos arenosos dos pacotes de dunas e, secundariamente, pela porção superior dos sedimentos da Formação Barreiras. A zona saturada é representada principalmente pela acumulação de água nos sedimentos da porção inferior da Formação Barreiras. Segundo Melo (1995), tais unidades hidroestratigráficas formam em conjunto um sistema aqüífero único, dominantemente do tipo livre, com semi-confinamentos localizados, denominado de Sistema Aqüífero Dunas-Barreiras.

Este aqüífero é responsável pelo abastecimento da maioria das cidades da faixa litorânea oriental do Rio Grande do Norte, incluindo a capital Natal. Sua constituição litológica é bastante diversificada, envolvendo desde argilas a arenitos conglomeráticos, embora se observe o predomínio de arenitos argilosos. O limite inferior deste aqüífero é o topo da seqüência carbonática mesozóica não aflorante da região, a qual foi individualizada em perfurações de poços como sendo constituída por sedimentos areno-argilosos a argilosos de composição calcífera e baixa potencialidade hidrogeológica, ou mesmo o embasamento cristalino, nas áreas próximas do contato deste último com a bacia sedimentar costeira (Lucena \& Queiroz 1996, Lucena et al. 2004). No tocante à condição hidrodinâmica, o
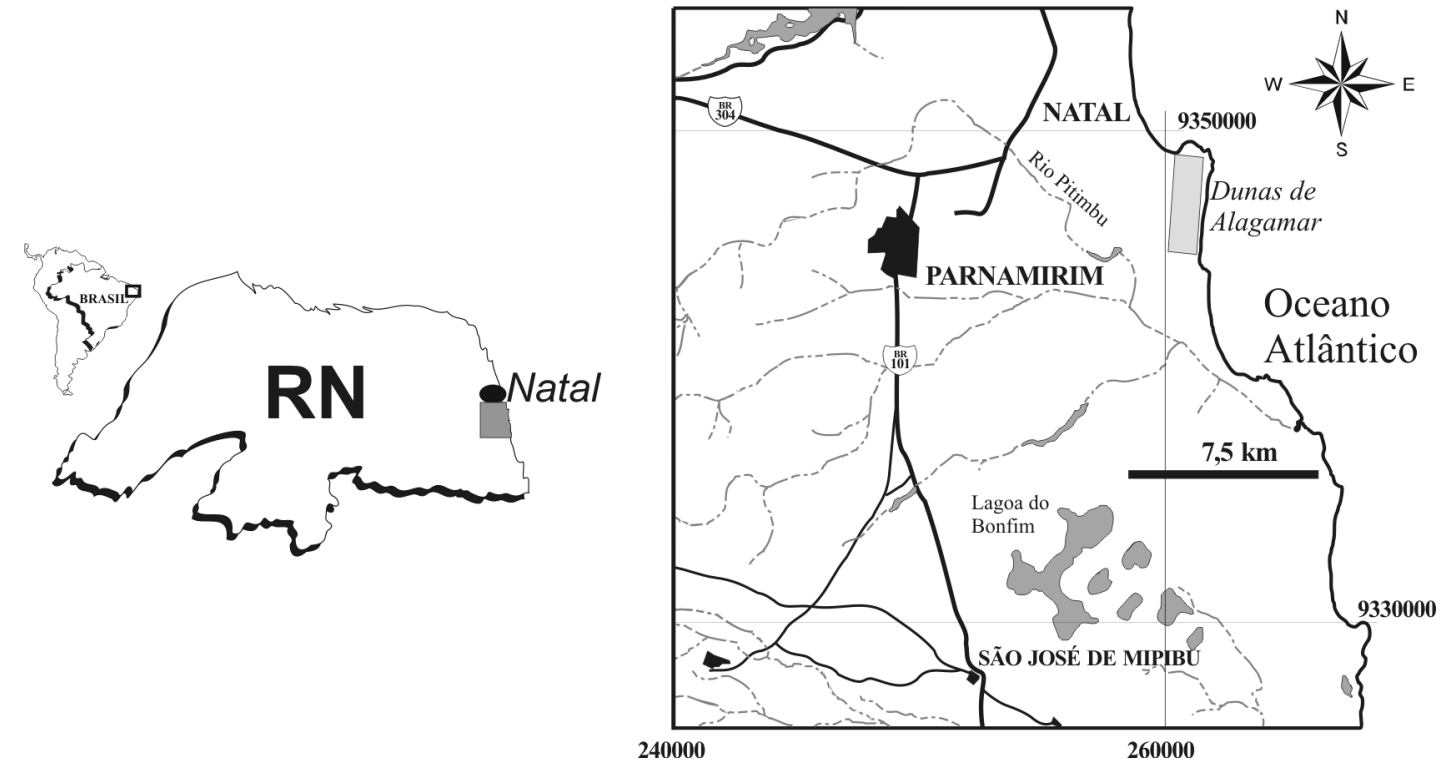

Figura 1 - Identificação da área de estudo (Centro de Lançamento da Barreira do InfernoCLBI e Dunas de Alagamar - Parnamirim-Natal/RN). 
Aqǘffero Barreiras comporta-se igualmente de maneira bastante variável, sobretudo na região sul de Natal até a fronteira com a Paraíba. Este comportamento pode apresentar-se de livre a semiconfinado, além de confinamentos localizados, onde a camada semiconfinante ou confinante, quando presente, é representada por horizontes ou lentes argilosas da própria Formação Barreiras, (IPT 1982).

\section{O LEVANTAMENTO GEOFÍSICO COM GPR} (GROUND PENETRATING RADAR)

Aspectos metodológicos e objetivos A utilização da metodologia GPR (Ground Penetrating Radar) ou GEORADAR na presente investigação geofísica deve-se a sua aplicabilidade e qualidade dos resultados, sobretudo em investigações pouco profundas e ambientes de reduzida condutividade elétrica, o que pode ser observado localmente na área de estudo. Diante desse contexto e de acordo com os objetivos gerais da presente pesquisa, o levantamento com GPR foi executado com vistas a auxiliar a caracterização do meio não saturado, particularmente a espessura local da unidade estratigráfica Dunas Móveis.

Os perfis foram coletados utilizando-se o equipamento SIR System 3000, fabricado pela GSSI (Geophysical Survey Systems Incorporated) e uma antena blindada com freqüência nominal de $200 \mathrm{MHz}$. O mesmo foi calibrado para coletar um traço a cada $0.04 \mathrm{~m}$ e com um range de tempo de $150 \mathrm{~ns}$. A velocidade de propagação do pulso eletromagnético dentro do campo de dunas foi estimada e ora adotada como sendo da ordem de $0.15 \mathrm{~m} /$ ns (Oliveira Jr. et al. 2003). Após a aquisição, os dados foram reformatados, editados e posteriormente processados com a finalidade de realçar feições geológicas, promover o correto posicionamento dos refletores e minimizar ruídos existentes nos dados originais de campo.

Resultados Os resultados são apresentados na forma de cortes verticais do subsolo, obtidos a partir do processamento dos dados de campo, proveniente de caminhamentos de $300 \mathrm{~m}$ (perfil 1), $270 \mathrm{~m}$ (perfil 2) e $330 \mathrm{~m}$ (perfil 3), sendo o primeiro executado paralelamente a linha de costa e os dois últimos executados perpendicularmente a praia (Fig. 2). Tais resultados possibilitaram uma investigação de até $15 \mathrm{~m}$ de profundidade aproximadamente, sendo possível a visualização de empilhamentos estratigráficos, espessura interpretada da Unidade Dunas Móveis e anomalias em geral.

Nos três perfis de GPR, observa-se claramente a presença de um refletor, o qual foi interpretado como sendo o contato entre a base do pacote formado por sedimentos arenosos (Dunas/lençóis de areia) e o topo da Formação Barreiras (informação esta calibrada com uma sondagem mecânica local destinada a execução de teste de permeabilidade vertical). A espessura deste pacote é bastante variável, principalmente, quando se analisa os

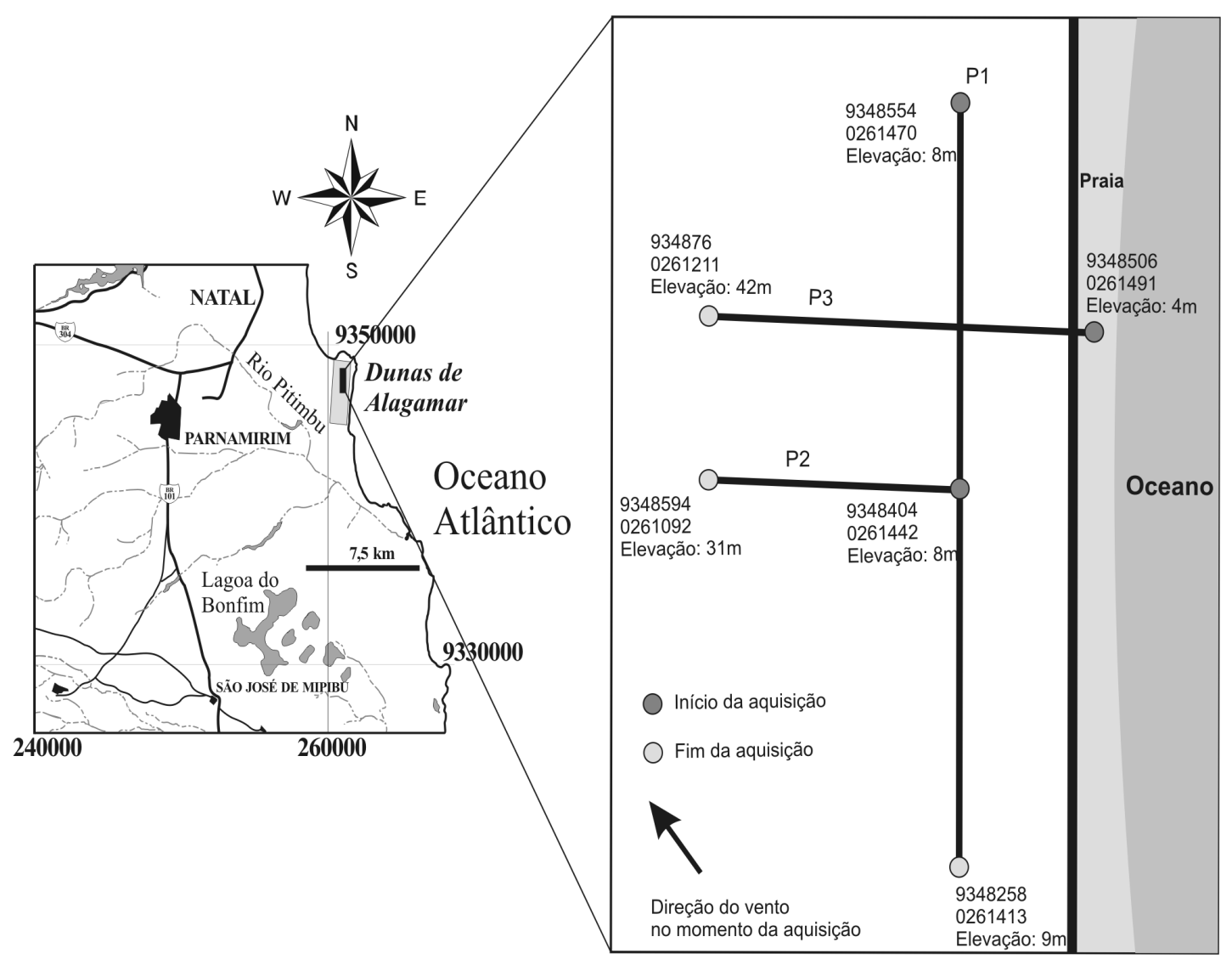

Figura 2 - Panorama geral do levantamento de GPR (coordenadas em UTM). 
dados coletados perpendicularmente à linha de costa.

Neste aspecto, as espessuras do pacote arenoso são de aproximadamente $3 \mathrm{~m}$ no perfil 1 , paralelo a linha de costa, atingindo até cerca de 6 e $11 \mathrm{~m}$ nos perfis 2 e 3 , perpendiculares a linha de costa, respectivamente (Figs. 3, 4 e 5).

Conforme reportado nos objetivos de que trata o tópico 1, a principal implicação dos dados obtidos no levantamento de GPR diz respeito à caracterização e determinação da espessura do meio insaturado e/ou dos patamares de dunas móveis na área de estudo. Nesse aspecto, o parâmetro "espessura" é preponderante, considerando-se uma eventual disposição local de águas residuais. As espessuras insaturadas ora caracterizadas projetam uma capacidade de acumulação d'água bastante limitada, além de conferir um grau de vulnerabilidade relativamente elevado para o Aqüífero Barreiras na área, fato este potencializado pela natureza litológica arenosa das dunas. Outro aspecto a ser ressaltado é a possível ocorrência de umidade inserida no próprio pacote de dunas, sugerido pela presença de refletores nos perfis 2 e 3 (Figs. 4 e 5). Tais feições podem decorrer simplesmente da infiltração de chuvas leves ocorridas na véspera do levantamento geofísico, ou mesmo sugerir um acúmulo d'água localizado em subsuperfície nesses sedimentos.

\section{PARÂMETROS HIDRÁULICOS DO MEIO IN- SATURADO}

Aspetos metodológicos e objetivos Os parâmetros hidráulicos do meio insaturado foram obtidos a partir da execução de ensaios de permeabilidade. Estes, realizados segundo a metodologia de nível variável (ABGE 1996), foram aplicados na obtenção de permeabilidades
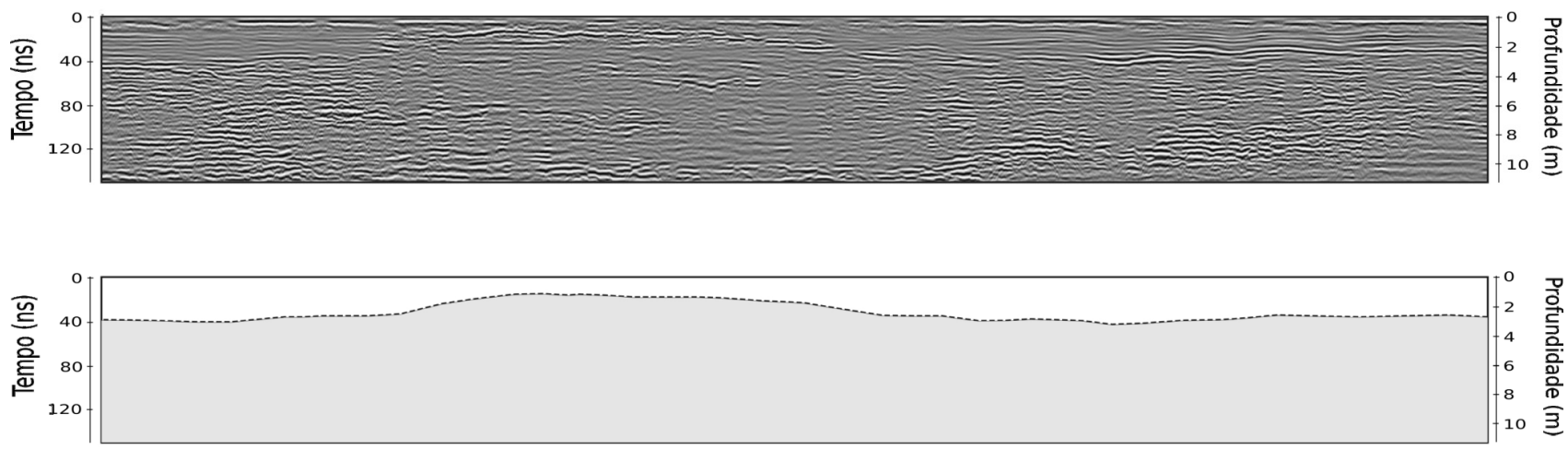

Sedimentos arenosos (Duna / Lençol de areia)

Formação Barreiras

Figura 3 - Perfil 1 (a) e sua interpretação (b) a partir do processamento dos dados de campo.
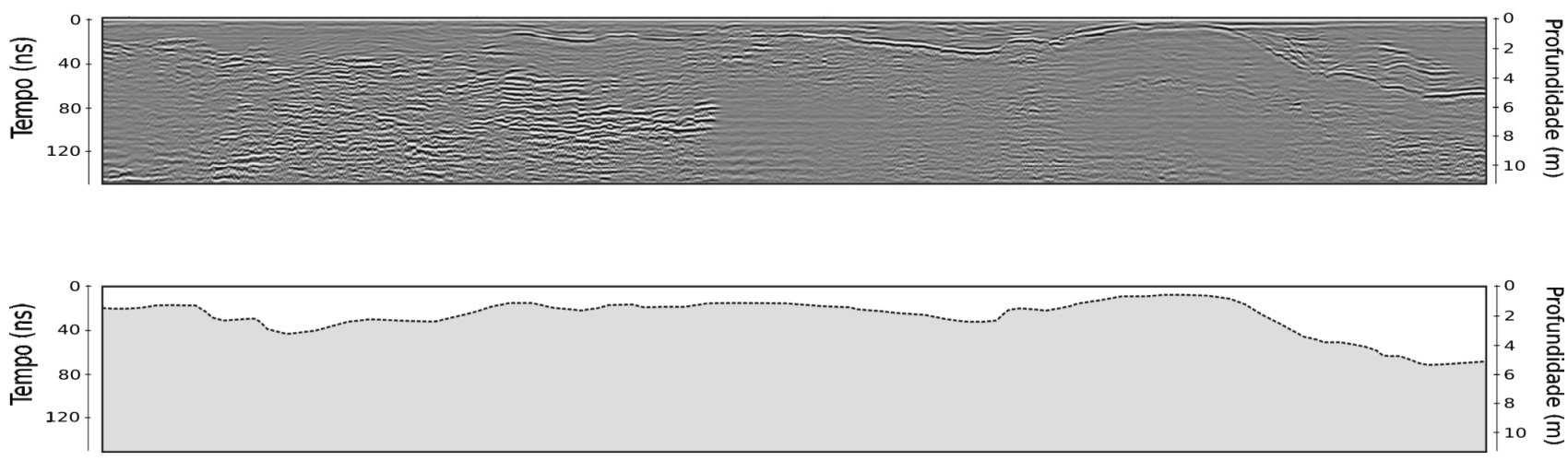

Sedimentos arenosos (Duna / Lençol de areia)

Formação Barreiras

Figura 4 - Perfil 2 (a) e sua interpretação (b) a partir do processamento dos dados de campo. 

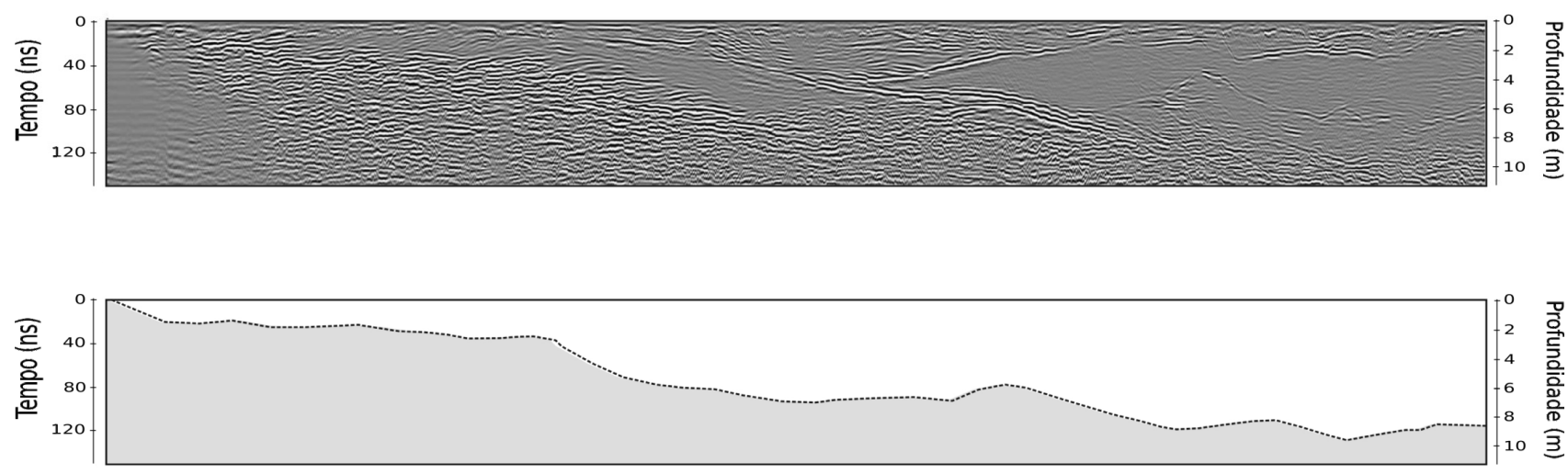

Sedimentos arenosos (Duna / Lençol de areia)

Formação Barreiras

Figura 5 - Perfil 3 (a) e sua interpretação (b) a partir do processamento dos dados de campo.

verticais e com vistas a subsidiar a análise da capacidade da Unidade Dunas de atuar como receptora dos efluentes em questão.

Os ensaios a nível variado consistem na alteração do nível d'água para uma posição em que se pode considerar como inicial do ensaio. Estimando-se que há uma tendência natural para o nível d'água retornar à posição original, efetuou-se o monitoramento da variação desse nível d'água com o tempo. Os ensaios foram executados com a introdução de água na sondagem e posterior monitoramento do rebaixamento do nível d'água a partir do nível inicial.

Considerando-se as características litológicas observadas na área estudada, pode-se propor a seguinte seqüência hidroestratigráfica (Fig. 6): (a) Uma unidade basal, composta essencialmente por sedimentos areno-argilosos a argilosos de composição calcífera e baixa potencialidade hidrogeológica, correlacionado ao topo da seqüência carbonática mesozóica não aflorante da região. Corresponde ao limite inferior do Sistema Aqüífero Dunas-Barreiras definido por Melo (1995); (b) Uma unidade intermediária, correspondendo a sedimentos de composição areno-argilosa a conglomerática, correlacionado a Formação Barreiras. Esses sedimentos podem ser descritos segundo duas subunidades: uma basal, de composição arenosa a areno-argilosa, por vezes conglomerática, correspondendo à unidade hidroestratigráfica onde é preferencialmente acumulada a água subterrânea do Sistema Aqǘf́rero Dunas-Barreiras; outra superior, correspondendo a sedimentos de composição argilosa a argilo-arenosa, que pode ou não condicionar a subunidade basal a confinamentos/semiconfinamentos localizados; (c) Sobreposta à seqüência descrita anteriormente repousam sedimentos quaternários correlacionados a corpos dunares.

Dessa forma, o conjunto formado pelos sedimentos da Formação Barreiras e dunas tende a formar um aqüífero único, correlacionado ao Sistema Aqüífero Dunas-Barreiras definido por Melo (1995). A caracte-

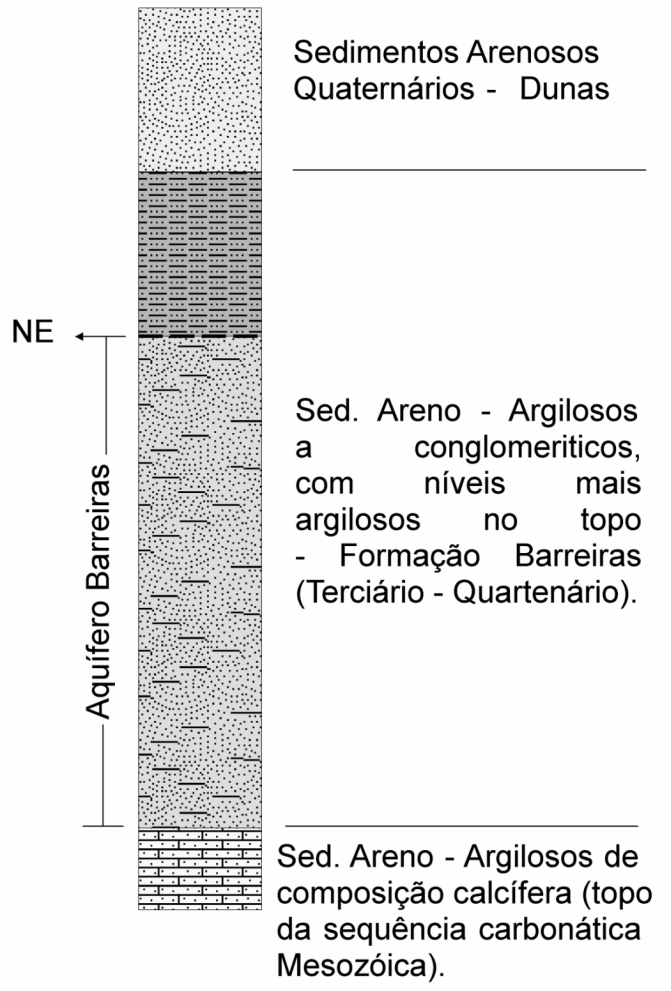

Figura 6 - Perfil hidroestratigráfico conceitual da área das Dunas de Alagamar, situada no setor nordeste do Centro de Lançamento da Barreira do Inferno-CLBI, Parnamirim-RN.

rização das relações hidráulicas existentes entre essas unidades hidroestratigráficas foi analisada a partir do desenvolvimento de 05 (cinco) ensaios de permeabilidade (EP) na zona insaturada da área estudada, sendo 03 (três) deles executados nos sedimentos dunares e os 
outros dois desenvolvidos na subunidade superior da Formação Barreiras (sedimentos argilosos a argilo-arenosos). Os testes desenvolvidos nas dunas foram realizados em três profundidades diferentes objetivando caracterizar o comportamento hidráulico ao longo da espessura dessa unidade. Os referidos ensaios foram realizados sem o auxílio de revestimento provisório, estes adotados na prevenção de desmoronamentos, a exceção do ensaio EP-03.

O cálculo da permeabilidade foi efetuado segundo as equações 1 e 2 apresentadas a seguir, respectivamente se o ensaio for realizado sem o auxílio de revestimento provisório, ou fazendo uso desse mecanismo.

$$
K=\frac{\Delta h}{\Delta t}\left(\frac{r}{R}\right)^{2}
$$

$$
K=\frac{\Delta h}{\Delta t} \frac{d_{1}{ }^{2}}{8 h_{0} \sqrt{d L}}
$$

Onde:

$$
\begin{aligned}
& \mathrm{K}=\text { Permeabilidade }(\mathrm{cm} / \mathrm{s}) ; \\
& \Delta \mathrm{h}=\text { Variação do nível d'água; } \\
& \Delta \mathrm{t}=\text { Variação de tempo; } \\
& \mathrm{r}=\text { raiqu da sondagem; } \\
& \mathrm{R}=\sqrt{h+r^{2}}, \text { onde } \mathrm{h} \text { corresponde a altura do }
\end{aligned}
$$

nível d'água inicial com relação à base da sondagem. sório;

$\mathrm{d}_{1}^{2}=$ Diâmetro interno do revestimento provi-

$\mathrm{h}_{0}=$ Altura entre a metade do comprimento do intervalo testado (sem revestimento) até o nível d'água inicial;

d = Diâmetro da sondagem;

$\mathrm{L}=$ Comprimento do intervalo testado (sem revestimento).

Obtendo-se o coeficiente de permeabilidade, os materiais geológicos testados foram classificados em: pedregulhos; areias; areias finas siltosas e argilosas, ou siltes argilosos; argilas, ainda de acordo com a metodologia proposta pela ABGE 1996 (Tab. 1).

Resultados Um resumo descritivo geral das características dos ensaios de permeabilidade realizados é apresentado na tabela 2 .

BALANÇO HÍDRICO E O CENÁRIO LOCAL DE VARIAÇÕES DE ARMAZENAMENTO Dados obtidos por Lucena (2005) no balanço hídrico de Thornthwaite para a área de Natal e adjacências (Bacia do Rio Pirangi) dão conta de valores de evapotranspirações reais de 1.081,14 mm/ano, déficit de 471,91 mm/ano, excedente de 501,94 mm/ano e escoamento superficial de $501,14 \mathrm{~mm} / \mathrm{ano}$ (Tabs. $3 \mathrm{e} \mathrm{4}$ ). As reservas d'água do solo começam a se constituir a partir de março, atingindo a saturação em abril (admitida altura máxima d'água de 100 mm susceptível de ser armazenada no solo). Nos meses de maio, junho e julho ocorre um excedente d'água, constituindo-se num escoamento superficial. Os meses de agosto, setembro e outubro marcam o período de perda d'água do solo, culminando com um déficit hídrico nos meses de novembro, dezembro, janeiro e fevereiro, onde o regime pluviométrico é insuficiente para assegurar reservas d'água úteis no solo.

A compreensão das variações de volume armazenado no sistema Dunas, passa necessariamente pelo entendimento das variações de volume armazenado ocorridas no Aqüífero Barreiras sotoposto, face a conexão hidráulica presente entre a Unidade Dunas e a Formação Barreiras (Melo 1995). Nesse contexto, pode-se vislumbrar que um aporte hídrico natural e/ou artificial (efluentes tratados) nas dunas, certamente chegará às camadas não saturadas da Formação Barreiras (estas com espessuras não superiores a $15 \mathrm{~m}$, conforme informações de um poço de pesquisa executado nas proximidades) e posteriormente ao aqǘfero homônimo, tendo em vista, principalmente, a elevada porosidade dessas areias eólicas. Esta descarga de transferência das dunas para a zona não saturada da Formação Barreiras, entretanto, seria regida por permeabilidades verticais da ordem de $10^{-2}$ e $10^{-4} \mathrm{~cm} / \mathrm{s}$, respectivamente.

Diante dessa perspectiva, considerando os dados obtidos no balanço hídrico regional, especificamente aqueles de precipitação média e evapotranspiração, somados com os resultados dos ensaios de infiltração e geometria da zona não saturada (Dunas), foi efetuado um balanço hidrogeológico simplificado desse sistema (Dunas). Para tanto, adotou-se parâmetros de entrada (precipitação média anual-P e descarga anual prevista de efluentes-D) e saída (evapotranspiração real-ETR e vazão transferida das dunas para a Formação Barreiras- $\mathrm{Q}_{\mathrm{T}}$ ), espessura média de $7 \mathrm{~m}$, área de $750.000 \mathrm{~m}^{2}(2.500 \mathrm{~m}$ x $300 \mathrm{~m})$ e porosidade total de $40 \%$, de acordo com a equação 3 .

$$
P+Q_{E}-E T R-Q_{T}=\Delta S
$$

Onde:

$$
\text { P: } 1.583 \mathrm{~mm} / \mathrm{ano} \times 750.000 \mathrm{~m}^{2}=1.187 .250 \mathrm{~m}^{3} /
$$

ano

$\mathrm{Q}_{\mathrm{E}}$ (vazão de efluentes): $5.000 \mathrm{~m}^{3} / \mathrm{h} \times 24 \mathrm{~h} \mathrm{x}$ 365 dias $=43.800 .000 \mathrm{~m}^{3} /$ ano

ETR: $1081,14 \mathrm{~mm} /$ ano $x 750.000 \mathrm{~m}^{2}=810.750$ $\mathrm{m}^{3} / \mathrm{ano}$

$$
\mathrm{Q}_{\mathrm{T}}: \mathrm{Q}=\mathrm{K} \times \mathrm{A} \times \eta_{\mathrm{EF}} \%=10^{-4} \mathrm{~cm} / \mathrm{s} \times 750.000 \mathrm{~m}^{2}
$$
$\mathrm{x} 0,1=2.362 .500 \mathrm{~m}^{3} / \mathrm{ano}$

Esta descarga transferida $\left(\mathrm{Q}_{\mathrm{T}}\right)$ das dunas para a Formação Barreiras e aqüífero homônimo foi mensurada adotando-se uma velocidade de percolação aproximadamente igual a permeabilidade vertical da porção superior não saturada da Formação Barreiras, segundo um gradiente hidráulico unitário (lei de Darcy, in Feitosa \& Manoel Filho 1997) e adotando-se uma porosidade média efetiva do topo da Formação Barreiras de $10 \%$ (valor máximo compatível com arenitos argilosos/ argilitos arenosos).

O valor positivo obtido para a variação de armazenamento $(\Delta \mathrm{S})$ de cerca de $41.814 .000 \mathrm{~m}^{3}$ /ano não se compatibiliza com o volume disponível na formação de dunas locais (cerca de $2.100 .000 \mathrm{~m}^{3}$, adotando-se uma espessura média de $7 \mathrm{~m}$, área de $750.000 \mathrm{~m}^{2}$ e po- 
Tabela 1 - Padrões de valores de permeabilidade (K) para diferentes materiais geológicos (Modificado de $A B G E$ 1996).

\begin{tabular}{|c|c|c|c|c|c|c|c|c|}
\hline $\mathrm{K}(\mathrm{cm} / \mathrm{s})$ & & $10^{2}$ & 1 & $10^{-2}$ & $10^{-4}$ & $10^{-6}$ & $10^{-8}$ & \\
\hline $\begin{array}{l}\text { Material } \\
\text { geológico }\end{array}$ & \multicolumn{2}{|l|}{ Pedregulhos } & \multicolumn{2}{|c|}{ Areias } & \multicolumn{3}{|c|}{$\begin{array}{c}\text { Areias finas siltosas e argilosas, siltes } \\
\text { argilosos }\end{array}$} & Argilas \\
\hline
\end{tabular}

Tabela 2 - Resumo das características gerais dos ensaios de permeabilidade.

\begin{tabular}{c|c|c|c|c|c}
\hline \multirow{2}{*}{$\begin{array}{c}\text { Ensaio de } \\
\text { permeab. }\end{array}$} & \multicolumn{2}{|c|}{ Localização } & $\begin{array}{c}\text { Prof. da } \\
\text { sondagem }(\mathrm{m})\end{array}$ & $\begin{array}{c}\text { Intervalo testado } \\
(\mathrm{m})\end{array}$ & Observações \\
\cline { 2 - 3 } EP-01 & 261.062 & 9.345 .118 & 5,0 & $0,0-5,0$ & Formação Barreiras (porção superior) \\
\hline EP-02 & 261.528 & 9.348 .924 & 1,0 & $0,0-1,0$ & Formação Barreiras (porção superior) \\
\hline EP-03 & 261.047 & 9.345 .134 & 1,70 & $0,5-1,7$ & $\begin{array}{c}\text { Sedimentos dunares; sondagem revestida } \\
\text { com tubo PVC de 0,0 a 0,5m para evitar } \\
\text { desmoronamentos }\end{array}$ \\
\hline EP-04 & 261.046 & 9.345 .130 & 0,5 & $0,0-0,5$ & Sedimentos dunares \\
\hline EP-05 & 261.046 & 9.345 .132 & 1,0 & $0,0-1,0$ & Sedimentos dunares \\
\hline
\end{tabular}

Tabela 3 - Balanço hídrico mensal para a área de Natal e adjacências (meses de janeiro a junho) segundo metodologia de Thorntwaite (Lucena 2005). Dados de precipitação média: 1911-2000; Dados de temperatura e ETP: 1960-1990 (P-Precipitação; ETP-Evapotranspiração Potencial; P-ETPDiferença entre a Precipitação e a Evapotranspiração Potencial; $\triangle_{2} \mathrm{H}_{2}$-Variação de água no solo; ETR-Evapotranspiração Real).

\begin{tabular}{l|c|c|c|c|c|c}
\hline Parâmetro / Mês & JAN & FEV & MAR & ABR & MAI & JUN \\
\hline Precip. (mm) & 55,63 & 108,77 & 205,53 & 256,75 & 246,89 & 263,73 \\
\hline ETP & 129,91 & 116,71 & 133,80 & 112,44 & 109,14 & 107,96 \\
\hline P-ETP & $-74,28$ & $-7,94$ & 71,73 & 144,31 & 137,75 & 155,77 \\
\hline$\Delta$ H$_{2}$ O Solo & --- & --- & $+71,73$ & $+28,27$ & --- & --- \\
\hline Reserva útil (mm) & 0,0 & 0,0 & 71,73 & 100,0 & 100,0 & 100,0 \\
\hline ETR & 55,63 & 108,77 & 133,80 & 112,44 & 109,14 & 107,96 \\
\hline D (déficit) & 74,28 & 7,94 & --- & --- & --- & -- \\
\hline S (excesso) & --- & --- & --- & 116,04 & 137,75 & 155,77 \\
\hline R (escoamento) & 1,72 & 0,86 & 0,0 & 58,02 & 97,89 & 126,83 \\
\hline
\end{tabular}

Tabela 4 - Balanço hídrico mensal para a área de Natal e adjacências (meses de julho a dezembro) segundo metodologia de Thorntwaite (Lucena 2005). Dados de precipitação média: 1911-2000; Dados de temperatura e ETP: 1960-1990. (P-Precipitação; ETP-Evapotranspiração Potencial; P-ETPDiferença entre a Precipitação e a Evapotranspiração Potencial; $\triangle_{2} \mathrm{H}_{2}$-Variação de água no solo; ETR-Evapotranspiração Real).

\begin{tabular}{l|c|c|c|c|c|c|c}
\hline Parâmetro / Mês & JUL & AGO & SET & OUT & NOV & DEZ & ANO \\
\hline Precip. (mm) & 214,17 & 115,03 & 53,05 & 19,41 & 18,68 & 25,44 & 1583,06 \\
\hline ETP & 121,79 & 123,20 & 140,10 & 154,49 & 157,27 & 146,24 & 1553,05 \\
\hline P-ETP & 92,38 & $-8,17$ & $-87,05$ & $-135,08$ & $-138,59$ & $-120,80$ & --- \\
\hline$\Delta \mathrm{H}_{2} \mathrm{O}$ Solo & --- & $-8,17$ & $-87,05$ & $-4,78$ & --- & --- & --- \\
\hline Reserva útil (mm) & 100,0 & 91,83 & 4,78 & 0,0 & 0,0 & 0,0 & --- \\
\hline ETR & 121,79 & 123,20 & 140,10 & 24,19 & 18,68 & 25,44 & 1081,14 \\
\hline D (déficit) & --- & --- & --- & 130,30 & 138,59 & 120,80 & 471,91 \\
\hline S (excesso) & 92,38 & --- & --- & --- & --- & -- & 501,94 \\
\hline R (escoamento) & 109,61 & 54,81 & 27,41 & 13,71 & 6,86 & 3,43 & 501,15 \\
\hline
\end{tabular}


rosidade total de 40\%). Dessa forma, invariavelmente, o cenário local evoluiria para uma completa saturação de todo o sistema local de dunas, mediante um aporte constante de efluentes da magnitude daquela informada, ocasionando o afloramento desses últimos e o respectivo fluxo superficial no sentido da praia.

Ressalta-se que, face às simplificações conveniadas no presente cálculo, não se considerou escoamento superficial (por se tratar de areias dunares e ausência local de drenagens superficiais), bem como a umidade presente no próprio pacote de dunas, evidenciado nas perfurações destinadas aos ensaios de permeabilidade e sugerido pelo levantamento geofísico de GPR.

Por outro lado, a elevada diferença dos valores de permeabilidade vertical reportada entre as dunas e o topo da Formação Barreiras $\left(10^{-2}\right.$ e $10^{-4} \mathrm{~cm} / \mathrm{s}$, respectivamente) é traduzida temporalmente num volume infiltrado através da porção superior da Formação Barreiras significativamente inferior às descargas de efluentes previstas para serem dispostas nas dunas. Com isso, a tendência é que ocorra uma elevação da carga hidráulica no sistema Dunas-Barreiras local, requerendo a existência de uma maior espessura da unidade estratigráfica Dunas destinada ao armazenamento do volume de efluentes. Este cenário seria bastante agravado após o início da quadra chuvosa principal no litoral leste do Estado, onde a elevação do nível freático seria mais evidente. Adotando-se a relação matemática da porosidade (equação 4, Feitosa \& Manoel Filho 1997), podese estimar esta elevação da seguinte forma:

$$
\eta \%=\mathrm{V}_{\mathrm{v}} / \mathrm{V}_{\text {total }}=\mathrm{V}_{\text {infiltrado }} / \text { Área } \times \mathbf{H}
$$

O volume infiltrado é dado pela soma da descarga de efluentes prevista para os meses de Abril a Julho e o excedente que infiltraria nesse mesmo período (evapotranspiração real subtraído da precipitação), subtraído da descarga transferida $\left(\mathrm{Q}_{\mathrm{T}}\right)$ no quadrimestre das dunas para a Formação Barreiras. Os valores dos parâmetros são:

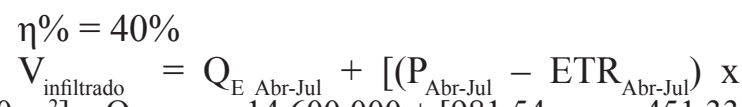
$\left.750.000 \mathrm{~m}^{2}\right]-\mathrm{Q}_{\mathrm{T} \text { Abr-Jul }}=14.600 .000+[981,54 \mathrm{~mm}-451,33$ $\left.\mathrm{mm}\left(\mathrm{x} 750.000 \mathrm{~m}^{2}\right)\right]-787.500=14.210 .157 \mathrm{~m}^{3} /$ Quadrimestre

\section{Área $=750.000 \mathrm{~m}^{2}$}

Dessa forma, a referida elevação do nível freático na quadra chuvosa principal seria de 47,36 m, incompatível com a espessura média das Dunas Móveis de Alagamar que é da ordem de $7 \mathrm{~m}$, conforme o levantamento geofísico de GPR.

DISCUSSÃO DOS RESULTADOS E SÍNTESE CONCLUSIVA $O$ meio insaturado da área em estudo, composto por sedimentos arenosos de dunas sobrepostos a sedimentos argilosos da porção superior da Formação Barreiras, apresenta variações nas suas características hidráulicas.

As dunas evidenciaram elevados valores de permeabilidade (ordem de grandeza de $10^{-2} \mathrm{~cm} / \mathrm{s}$ ), indicando boas condições de infiltração de líquidos (águas de chuvas ou mesmo esgotos tratados) para a recarga do aqüífero. Porém, a porção basal do pacote de dunas mostra uma diminuição das condições de permeabilidade em função da proximidade dos sedimentos argilosos do topo da Formação Barreiras. Estes últimos apresentam baixos valores de permeabilidade vertical, podendo funcionar como um aquitard, ou seja, uma formação geológica (ou parte desta) com potencial para acumulação de água subterrânea, porém incapaz de transmitir quantidades significativas desta sob condições normais de gradientes hidráulicos. Devido à presença dessa camada do topo da Formação Barreiras com características de aquitard, há chances do Aqüífero Barreiras na área em estudo comportar-se como do tipo confinado ou semi-confinado, fato este a ser confirmado no decorrer de etapas subseqüentes do estudo.

Esta condição hidrodinâmica de confinamento aparente do Aqüífero Barreiras observada também no poço de pesquisa (sugerido por observações e parâmetros construtivos do poço, testes de permeabilidade vertical e teste de influência da maré) favorece a diminuição local do grau de vulnerabilidade do aqǘf́ero, ressaltando-se o topo litologicamente argiloso deste último. Alternativamente, o resultado parcial do levantamento geofísico com GPR sugere uma vulnerabilidade elevada sob o ponto de vista da espessura do pacote arenoso de duna sobreposta. Entretanto, esta condição de semi-confinamento a confinamento, caso confirmada pelo teste de aqüífero a ser realizado, aponta para uma potencialização temporal de saturação do pacote de dunas (com espessuras médias de 7 metros), frente a uma estimativa de infiltração local de cerca de $5.000 \mathrm{~m}^{3} / \mathrm{h}$ de águas residuais (informação verbal da CAERN).

Considerando-se um cenário de eventual descarte de efluentes tratados numa área retangular de $2.500 \mathrm{~m}$ de comprimento por $300 \mathrm{~m}$ de largura, situada no extremo nordeste da área do CLBI conhecida como "Dunas de Alagamar", e adotando-se uma espessura média local do pacote de dunas de 7,0m, tem-se um volume total de $5.250 .000 \mathrm{~m}^{3}$. Entretanto, segundo Fetter (2001), areias bem selecionadas tal como localmente caracterizadas podem apresentar uma porosidade entre 25 e $50 \%$. Dessa forma, adimitindo-se o volume de dunas acima calculado com porosidade média de $40 \%$, tem-se um volume de vazios da ordem de $2.100 .000 \mathrm{~m}^{3}$. Esse valor representaria a capacidade máxima desse pacote/área aparentemente disponível para a infiltração de águas de chuvas ou mesmo efluentes tratados. Nesse contexto, a simulação efetuada no pacote estratigráfico das dunas, considerando aportes (descarga de efluentes e precipitação) e saídas do sistema (evapotranspiração e vazão efetivamente infiltrada na Formação Barreiras) no quadrimestre chuvoso da região litorânea leste do Estado, revelou que seria necessário uma espessura mínima de dunas da ordem de 50 metros, valor este destinado a comportar descargas naturais e artificiais da magnitude daquela reportada. Ressalta-se ainda que nesta simulação não foi considerada a ocorrência de 
águas subterrâneas armazenadas nas dunas, conforme sugerido no levantamento de GPR e verificado em uma sondagem de reconhecimento estratigráfico realizada nas imediações e previamente à execução do ensaio de permeabilidade local.
Agradecimentos Os autores agradecem a Companhia de Águas e Esgotos do Rio Grande do Norte-CAERN pelo financiamento do projeto de que trata o presente artigo e pela valorização da pesquisa como ferramenta de decisão no tocante a gestão dos recursos hídricos.

\section{Referências}

ASSOCIAÇÃO BRASILEIRA DE GEOLOGIA DE ENGENHARIA (ABGE). 1996. Ensaios de permeabilidade em solos - orientações para sua execução no campo. $3^{\text {a }}$ edição, São Paulo, Boletim 04.

Bezerra F.H.R., Saad A., Moreira J.A.M., Lins F.A.P.L., Nogueira A.M.B., Macedo J.W.P., Lucena L.R. F. de, Nazaré JR.D. 1993. Estruturação neotectônica do litoral de Natal-RN, com base na correlação entre dados geológicos, geomorfológicos e gravimétricos. In: SBG, Simpósio Nacional de Estudos Tectônicos, 4, Atas, Bol. 12, p. 317-321.

Coriolano A.C.F., Lucena L.R.F., Jardim de Sá E.F., Saad A. 1998. A deformação quaternária no litoral oriental do Rio Grande do Norte. In: SBG, Simpósio Nacional de Estudos Tectônicos, 8, Atas, p. 67-70.

Feitosa F.A.C. \& Manoel Filho J. (eds.) 1997. Hidrogeologia - conceitos e aplicações. 2a ed., Fortaleza, CPRM/ REFO, LABHID-UFPE, 391p.

INSTITUTO DE PESQUISAS TECNOLÓGICAS DO ESTADO DE SÃO PAULO S/A (IPT). 1982. Estudo hidrogeológico regional detalhado do Estado do Rio Grande do Norte. Relatório técnico IPT $\mathrm{n}^{\circ} 15.795,389 \mathrm{p}$. (Disponível na Secretaria de Meio Ambiente e Recursos Hídricos do Rio Grande do Norte (SEMARH - Governo do Rio Grande do Norte).

Lucena L.R.F. \& Queiroz M.A. 1996. Considerações sobre as influências de uma tectônica cenozóica na pesquisa e prospecção de recursos hídricos - o exemplo do litoral sul de Natal-RN, Brasil. Revista Águas Subterrâneas, 15:81-88.

Lucena L.R.F., Rosa Filho E.F., Bittencourt A.V.L. 2004. A potenciometria do Aqǘf́ro Barreiras no setor oriental da bacia do Rio Pirangi-RN e considerações sobre a relação com mananciais superficiais. Revista Águas Subterrâneas, 18:19-27.

Lucena L.R.F. 2005. Implicação da compartimentação estrutural no Aqüifero Barreiras na área da bacia do Rio Pirangi-RN. Curitiba, Tese de Doutoramento, Universidade Federal do Paraná, 151p.

Melo J.G. 1995. Impactos do desenvolvimento urbano nas águas subterrâneas de Natal/RN - Zona Sul. São Paulo, Tese de Doutoramento, Universidade de São Paulo, 196p.

Oliveira Jr J.G., Medeiros W.E., Vital H., Xavier Neto P., Stattegger K. 2003. GPR imaging of the internal structure of a sand dune in Rio Grande do Norte State, Brazil. Journal of Coastal Research, Special Issue, 35:271278.

Manuscrito ID 13339

Submetido em 21 de janeiro de 2009 Aceito em 21 de março de 2009 